\title{
Back mutations to the TEM-1 $\beta$-lactamase from TRC-1 lead to restored sensitivity to clavulanic acid
}

\author{
C. J. THOMSON and S. G. B. AMYES \\ Department of Medical Microbiology, The Medical School, University of Edinburgh, Teviot Place, \\ Edinburgh EH8 9AG
}

\begin{abstract}
Summary. Back mutations from the TRC-1 $\beta$-lactamase to the TEM-1 enzyme were selected in vitro.The revertant $\beta$-lactamase was obtained from Escherichia coli strain J62.2 carrying plasmid pUK901 which encodes the TRC-1 $\beta$-lactamase. The revertant was obtained after repeated subculture of $E$. coli J62.2 (pUK901) in amoxycillin $512 \mathrm{mg} / \mathrm{L}$ for 5 days. The revertant $\beta$-lactamase had the same pI as TEM-1 (5.4) and had restored inhibition by clavulanic acid (ID50 reduced from $4 \cdot 2 \mu \mathrm{M}$ to $0 \cdot 15 \mu \mathrm{M}$ ). The prevalence of these $\beta$-lactamases in the clinical population may be the result of a two-way flux, with mutations in both forward and backward directions.
\end{abstract}

\section{Introduction}

The most important mechanism of resistance to $\beta$ lactam antibiotics is the production of $\beta$-lactamases that catalyse hydrolysis of the $\beta$-lactam ring. ${ }^{1,2}$ Two strategies have been employed to overcome resistance mediated by $\beta$-lactamases. First, the development of new $\beta$-lactam antibiotics which, as a result of modifications in structure, are stable to hydrolysis by $\beta$-lactamases. Second, the use of $\beta$-lactamase inhibitors which, when administered with the $\beta$-lactam, protect it from hydrolysis by the $\beta$-lactamase. ${ }^{3,4}$

The TEM-1 enzyme is the most important $\beta$ lactamase encountered in gram-negative bacilli, both clinical isolates and normal flora. ${ }^{5,6}$ The ability of the later generation cephalosporins to select TEM-1 $\beta$ lactamase mutants with the ability to hydrolyse these cephalosporins is well documented. ${ }^{7}$ The vast majority of TEM-derived extended spectrum $\beta$-lactamases remain sensitive to inhibition by the $\beta$-lactamase inhibitors sulbactam, tazobactam and clavulanic acid, ${ }^{8}$ and it was thought unlikely that the TEM-1 enzyme would be capable of mutation to form new enzymes with increased resistance to $\beta$-lactamase inhibitors. However, TRC-1, a novel TEM-derived $\beta$-lactamase with increased resistance to $\beta$-lactamase inhibitors, was identified in a urinary Escherichia coli isolate in Edinburgh, ${ }^{9}$ and similar $\beta$-lactamases, termed TRI $\beta$ lactamases, have been found in clinical isolates in France. ${ }^{10}$ The TRC-1 $\beta$-lactamase can be selected from TEM-1 directly with a combination of amoxycillin and clavulanic acid; however, it has been demonstrated

Received 17 Oct. 1994; revised version accepted 14 Dec. 1994. that increased resistance to $\beta$-lactamase inhibitors is associated with a decrease in resistance to amoxycillin alone. ${ }^{11}$

The unexpected appearance of TEM $\beta$-lactamases with increased resistance to $\beta$-lactamase inhibitors has led to speculation about the impact that such enzymes may have on the successful clinical use of $\beta$-lactam plus $\beta$-lactamase inhibitor combinations. At present TRC-1 appears to be rare, although it is not clear if this is simply because few studies have looked specifically for this $\beta$-lactamase. Strains encoding this enzyme have only a moderate increase in resistance to co-amoxiclav, and may therefore be missed in routine sensitivity testing. ${ }^{11}$ Alternatively, the rarity of this enzyme may result from reduced activity of the $\beta$-lactamase against amoxycillin. To investigate if this latter point may have a role in determining the clinical success of the TRC- $1 \beta$-lactamase, the effect of amoxycillin challenge on the bacteria producing TRC-1 was examined.

\section{Materials and methods}

\section{Bacterial strain}

The strain used in the challenge experiments was E. coli strain J62.2 (pUK901). This strain is the TRC-1 producing transconjugant derived from the original TRC-1 producing clinical isolate (E. coli strain E307). ${ }^{9}$

\section{Challenge experiments}

E. coli strain $\mathrm{J} 62.2$ (pUK901) was grown in a series 


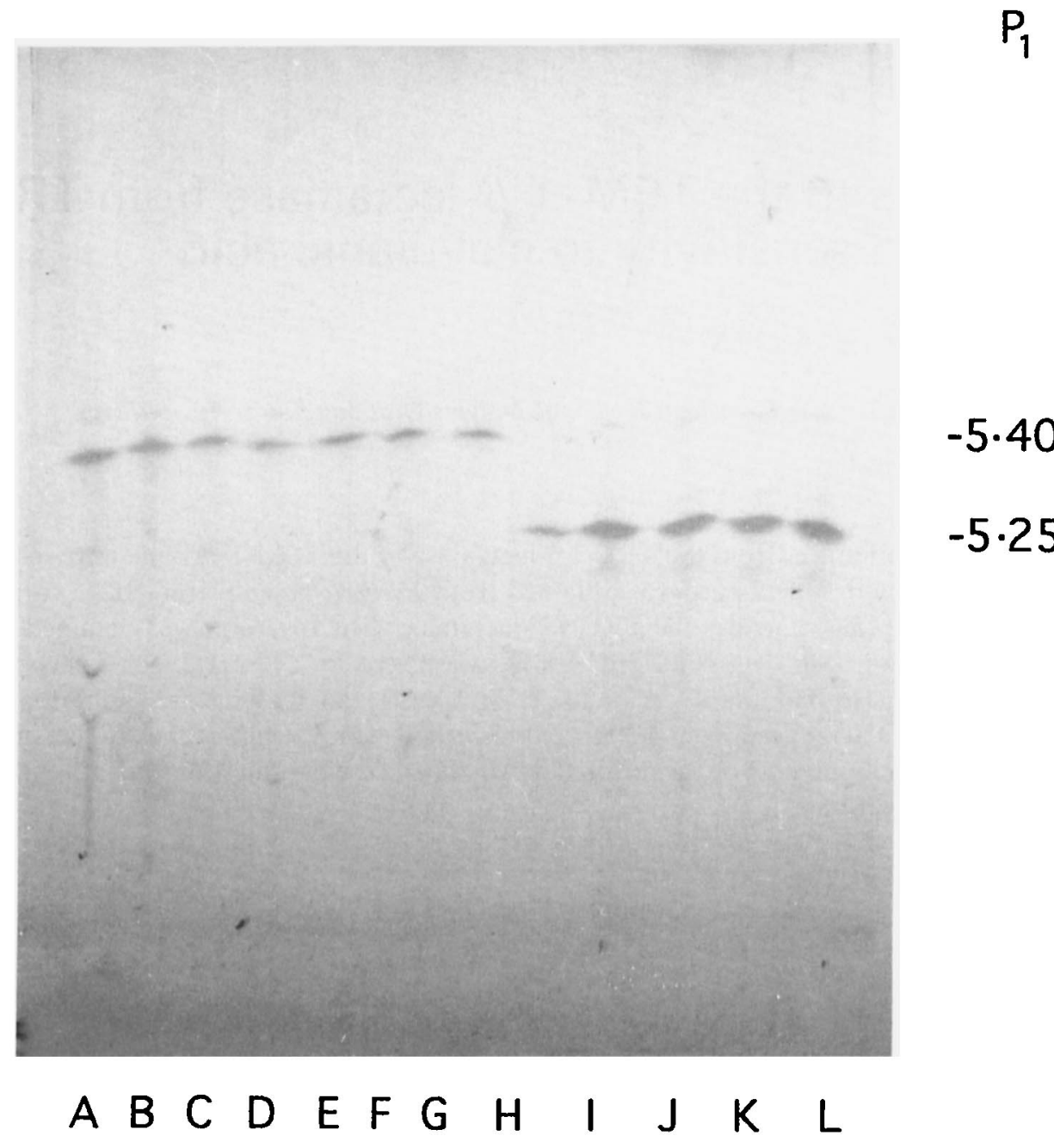

Fig. 1. $\beta$-Lactamase IEF profile of purified isolates. The IEF gel contained a 50:50 mixture of ampholines (pH range 3.5-10 and $\mathrm{pH}$ range 4-6). Tracks: A-F and I-L, $\beta$-lactamase from purified isolates obtained after challenge with amoxycillin $512 \mathrm{mg} / \mathrm{L}$ for 5 days; G, TEM-1 control strain; H, TRC-1 control strain.

of Oxoid IsoSensitest broths containing amoxycillin at concentrations of $0,128,256$ and $512 \mathrm{mg} / \mathrm{L}$ and incubated with agitation at $37^{\circ} \mathrm{C}$. At 24 -h intervals, each culture was subcultured into a further series of IsoSensitest broths containing the same range of amoxycillin concentrations. This procedure was repeated five times. Also, after each 24 -h period, bacteria were harvested from $10 \mathrm{ml}$ of the culture by centrifugation $(4500 \mathrm{~g} ; 15 \mathrm{~min})$ in a Heraeus Christ Bactifuge. The cell pellet was resuspended in $10 \mathrm{ml}$ of single strength Davis Mingioli medium, ${ }^{12}$ and $0 \cdot 1 \mathrm{ml}$ was spread on to IsoSensitest agar plates containing amoxycillin at the same concentration as the broth from which the culture was derived. Ten single colonies were purified on the same medium. The auxotrophic requirements of the colonies (L-proline, L-histidine and L-tryptophan dependency) were checked ${ }^{11}$ on Davis Mingioli minimal medium plates to confirm that they were $E$. coli $\mathrm{J} 62.2$.

\section{Plasmid analysis}

Plasmid DNA was extracted from $4.5 \mathrm{ml}$ of an overnight IsoSensitest broth culture by alkaline denaturation as described by Takahashi and
Nagano. ${ }^{13}$ The final DNA pellet was resuspended in $60 \mu \mathrm{l}$ of RNAase (Sigma) solution $(50 \mathrm{mg} / \mathrm{L}$ in sterile $\left.\mathrm{H}_{2} \mathrm{O}\right)$ and $18-\mu \mathrm{l}$ portions were digested with EcoRI (BRL), used according to the manufacturer's instructions. After electrophoresis at $60 \mathrm{v}$ for $18 \mathrm{~h}$ in agarose $0.8 \% \mathrm{w} / \mathrm{v}$ gels, DNA was visualised by staining with ethidium bromide $5 \mathrm{mg} / \mathrm{L}$ and examination on a flat bed UV source.

\section{$\beta$-Lactamase studies}

$\beta$-Lactamases for iso-electric focusing (IEF) were prepared from bacterial cells grown overnight on nutrient agar slopes. IEF was by the method of Matthew et al., ${ }^{14}$ with ampholine ranges as described in Results. $\beta$-Lactamase for inhibition studies was prepared from bacteria grown for $15 \mathrm{~h}$ in $1 \mathrm{~L}$ of nutrient broth. Bacteria were harvested by centrifugation $(5000 \mathrm{~g} ; 15 \mathrm{~min})$, washed and then resuspended in $5 \mathrm{ml}$ of $50 \mathrm{mM}$ sodium phosphate buffer, $\mathrm{pH} 7 \cdot 0$, disrupted by sonication and the cell debris was removed by centrifugation $(20000 \mathrm{~g}$; $30 \mathrm{~min}$ ). One-ml of this crude $\beta$-lactamase preparation was applied to a previously calibrated Sephadex G75 column $\left(2 \mathrm{~cm}^{2} \times 90 \mathrm{~cm}\right)$ and eluted with $50 \mathrm{~mm}$ sodium 
phosphate buffer. The collected fractions $(2 \mathrm{ml})$ were assayed for $\beta$-lactamase activity by spot testing with the chromogenic cephalosporin nitrocefin (Glaxo). Fractions showing peak $\beta$-lactamase activity were pooled and used for further analysis. All $\beta$-lactamase preparations were stored at $-20^{\circ} \mathrm{C}$ until required.

Spectrophotometric assay was performed as described previously. ${ }^{15}$ The decrease in absorbance of nitrocefin at $384 \mathrm{~nm}$ was monitored at $37^{\circ} \mathrm{C}$ in $50 \mathrm{~mm}$ sodium phosphate buffer, $\mathrm{pH} 7 \cdot 0$, in a Perkin Elmer Lambda-2 Double-Beam UV Spectrophotometer. Inhibition studies with clavulanic acid were performed with and without a 5-min pre-incubation of the inhibitor with the $\beta$-lactamase.

\section{Results}

\section{Challenge experiment}

E. coli J62.2 (pUK901) was challenged in IsoSensitest broth containing amoxycillin at concentrations of $0,128,256$ and $512 \mathrm{mg} / \mathrm{L}$. Growth was observed at all concentrations. Ten purified colonies from each challenge were analysed for their auxotrophic requirements on Davis-Mingioli minimal medium plates; all were confirmed to be $E$. coli J62.2.

\section{$\beta$-Lactamase analysis of challenged strains}

$\beta$-Lactamase production by the challenged strains was analysed by screening cleared lysates of bacterial sonicates with IEF on polyacrylamide gels containing ampholines of $\mathrm{pH}$ range $3 \cdot 5-10$, with TEM- 1 and TRC-1 $\beta$-lactamases as controls. At amoxycillin concentrations of 0,128 and $256 \mathrm{mg} / \mathrm{L}$, TRC-1 was produced by every isolate tested throughout the 5-day period. However, at an amoxycillin concentration of $512 \mathrm{mg} / \mathrm{L}$, four apparent revertants to TEM-1 were detected on day 4 , and by day 5 , isolates producing this $\beta$-lactamase predominated (six of 10 isolates).

\section{Analysis of strains isolated on day 5 after challenge with amoxycillin $512 \mathrm{mg} / \mathrm{L}$}

The 10 purified isolates from the challenge with amoxycillin $512 \mathrm{mg} / \mathrm{L}$ were examined in more detail. Initial IEF data suggested that six of these isolates

Table. ID50 of clavulanic acid for TRC-1 and putative TEM-1 $\beta$-lactamases obtained from isolates pre- and postchallenge with amoxycillin $512 \mathrm{mg} / \mathrm{L}$ for 5 days

\begin{tabular}{lcc}
\hline & \multicolumn{2}{c}{ ID50 $(\mu \mathrm{M})$ of clavulanic acid } \\
\cline { 2 - 3 }$\beta$-Lactamase & No pre-incubation & With pre-incubation* \\
\hline TRC-1 control & 50 & $4 \cdot 2$ \\
TRC-1 post-challenge & 50 & $5 \cdot 0$ \\
TEM-1 control & $0 \cdot 54$ & $0 \cdot 01$ \\
TEM-1 revertant & $0 \cdot 80$ & $0 \cdot 15$ \\
\hline
\end{tabular}

*Pre-incubation of clavulanic acid with the $\beta$-lactamase for $5 \mathrm{~min}$.

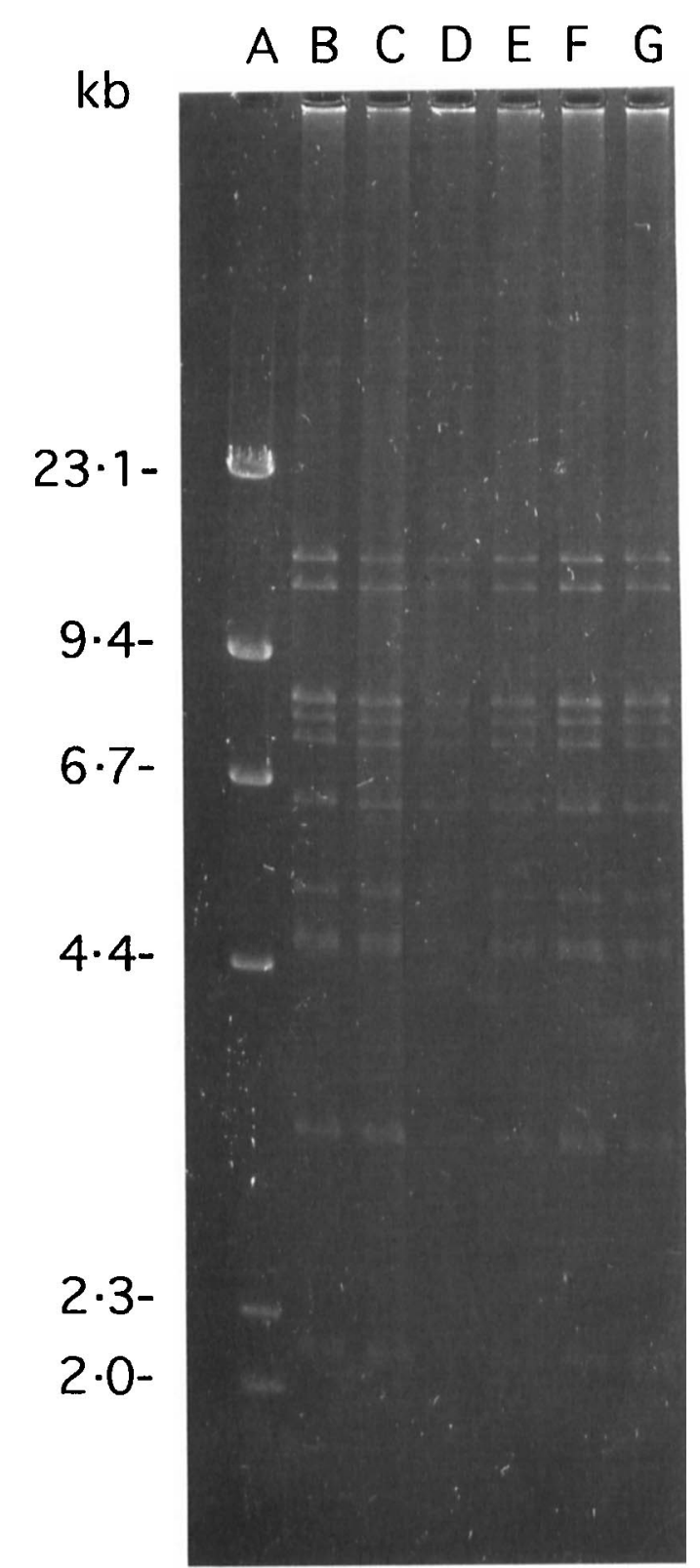

Fig. 2. EcoRI restriction endonuclease digests of purified plasmid DNA from strains encoding putative TEM-1 and TRC-1 isolated after challenge with amoxycillin $512 \mathrm{mg} / \mathrm{L}$ for 5 days. Tracks: A, $\lambda$-HindIII digest; B, E. coli (pUK901) unchallenged parent strain; $\mathbf{C}$, as $\mathbf{B} ; \mathbf{D}$, post-challenge isolate producing putative TEM-1; E, as $\mathbf{D} ; \mathbf{F}$, post-challenge isolate producing TRC-1; G, as F.

were no longer producing TRC-1, but may have reverted to producing TEM- 1 . The $\beta$-lactamase produced by each isolate was examined on a narrow range IEF gel containing a mixture of ampholines of pH range 3.5-10 and 4-6 (fig. 1). This confirmed that six of the isolates produced a $\beta$-lactamase that cofocused with TEM-1.

Plasmid DNA was extracted from the parent $E$. coli J62.2 (pUK901) strain and from isolates producing TRC-1 and TEM- 1 after challenge with amoxycillin $512 \mathrm{mg} / \mathrm{L}$ for 5 days. Restriction endonuclease analysis of purified plasmid DNA demonstrated that both TEM-1 and TRC-1 producers contained the same plasmid as the parent strain (fig. 2). 


\section{Biochemical analysis of TRC-1 and TEM-1 revertants}

Biochemical properties of TRC-1 and TEM-1 isolated from post-challenge strains were determined and compared to TRC-1 and TEM-1 from controls. The ID50 values for clavulanic acid were determined and demonstrated that reversion to TEM-1 was accompanied by a loss of resistance to clavulanic acid, with the ID50 decreasing from $4.2 \mu \mathrm{m}$ for TRC-1 to $0 \cdot 15 \mu \mathrm{M}$ for TEM-1 revertants (table).

\section{Discussion}

The use of $\beta$-lactam antibiotics in combination with $\beta$-lactamase inhibitors has proved to be one of the most effective ways of combating $\beta$-lactamasemediated resistance. ${ }^{3,4}$ It was suggested initially that the only likely cause of resistance was from strains that hyperproduce the TEM-1 $\beta$-lactamase. ${ }^{16,17}$ However, while such strains do indeed have increased resistance to $\beta$-lactam plus $\beta$-lactamase inhibitor combinations, the frequency of such strains does not appear to have increased since the introduction of inhibitor combinations into clinical practice. ${ }^{18}$ It had been thought unlikely that the TEM-1 $\beta$-lactamase would be capable of mutation to resistance to suicide inhibitors, but the TEM $\beta$-lactamase has shown a remarkable capacity to evolve to overcome changes in $\beta$-lactam design. TRC-1 was the first clinically isolated TEM $\beta$-lactamase derivative that showed an increase in resistance to $\beta$-lactamase inhibitors. ${ }^{9}$ There have been reports of similar $\beta$-lactamases in France, ${ }^{10}$ and

\section{References}

1. Medeiros AA. $\beta$-Lactamases. Br Med Bull 1984; 40: 18-27.

2. Sanders CC, Sanders WE. Beta-lactam resistance in Gramnegative bacteria - global trends and clinical impact. Clin Infect Dis 1992; 15: 824-839.

3. Thomson CJ, Amyes SGB. Prospects for expanding the use of $\beta$-lactamase inhibitors. $J$ Med Microbiol 1992; 37: 297-298.

4. Rolinson GN. Evolution of $\beta$-lactamase inhibitors. Rev Infect Dis 1991; 13 Suppl 9: S727-S732.

5. Thomson CJ, Amyes SGB. Molecular epidemiology of the plasmid-encoded TEM-1 $\beta$-lactamase in Scotland. Epidemiol Infect 1993; 110: 117-125.

6. Shanahan PMA, Thomson CJ, Amyes SGB. $\beta$-Lactam resistance in aerobic commensal faecal flora. Int $J$ Chemother 1994; 3 : 259-266.

7. Philippon A, Labia R, Jacoby G. Extended-spectrum $\beta$ lactamases. Antimicrob Agents Chemother 1989; 33: 1131-1136.

8. Payne DJ, Cramp R. Determination of $\mathrm{ID}_{50}$ values for 35 plasmid mediated $\beta$-lactamases. Abstracts of the First International Congress on the Management of Infection 1992; 10B7: 65 .

9. Thomson CJ, Amyes SGB. TRC-1: emergence of a clavulanic acid-resistant TEM $\beta$-lactamase in clinical strain. FEMS Microbiol Lett 1992; 91 : 113-118.

10. Vedel G, Belaaouaj A, Gilly L et al. Clinical isolates of Escherichia coli producing TRI $\beta$-lactamases: novel TEMenzymes conferring resistance to $\beta$-lactamase inhibitors. $J$ Antimicrob Chemother 1992; 30: 449-462.

11. Thomson CJ, Amyes SGB. Selection of variants of the TEM- 1 $\beta$-lactamase, encoded by a plasmid of clinical origin, with increased resistance to $\beta$-lactamase inhibitors. $J$ Antimicrob Chemother 1993; 31 : 655-664.

12. Davis BD, Mingioli ES. Mutants of Escherichia coli requiring methionine or vitamin B12. $J$ Bacteriol $1950 ; 60$ : 17-28. possibly from other centres in the UK. ${ }^{19}$ Sequence analysis has demonstrated that resistance can result from changes of arginine-244 to cysteine or serine, or a change of methionine- 69 to leucine.$^{20}$ Mutation to increased resistance of TEM-1 to $\beta$-lactamase inhibitors is, however, accompanied by a decrease in efficiency against simple penicillins when measured both by kinetic parameters and by MIC. ${ }^{11,21}$

At present, TEM enzymes resistant to $\beta$-lactamase inhibitors appear to be rare, and this may result from their decreased efficiency against penicillins. The findings of this study demonstrate for the first time that it is possible for back-mutations to the parent TEM $\beta$-lactamase to be selected. It may be that similar changes are possible in vivo, and that the prevalence of these $\beta$-lactamases is the result of a two-way flux, with mutations in both the forward and backward directions. In this respect it is tempting to speculate on the role that the relative ratios of inhibitor to $\beta$-lactam agent have on the process; it is possible that the greater the amount of inhibitor, the greater the pressure towards TRC-1, and vice versa. $\beta$-Lactam plus $\beta$ lactamase inhibitor combinations are available in the UK only in fixed proportions, although these are reformulated periodically. However, $\beta$-lactamaseinhibitors are available in some other countries as separate compounds. The influence of this availability on the selection of resistance has not as yet been addressed.

We thank the Wellcome Trust for grant no. 34079/1.5 which funded this work.

13. Takahashi S, Nagano Y. Rapid procedure for isolation of plasmid DNA and application to epidemiological analysis. $J$ Clin Microbiol 1984; 20: 608-613.

14. Matthew M, Harris AM, Marshall MJ, Ross GW. The use of analytical isoelectric focusing for detection and identification of $\beta$-lactamases. $J$ Gen Microbiol $1975 ; \mathbf{8 8}$ : 169-178.

15. Reid AJ, Amyes SGB. Plasmid penicillin resistance in Vibrio cholerae: identification of new $\beta$-lactamase SAR-1. Antimicrob Agents Chemother 1986; 30: 245-247.

16. French G, Ling J. Amoxycillin/clavulanate resistant Escherichia coli. Lancet 1988; 1: 704

17. Sanders CC, Iaconis JP, Bodey GD, Samonis G. Resistance to ticarcillin-potassium clavulanate among clinical isolates of the family Enterobacteriaceae: role of PSE- $1 \beta$-lactamase and high levels of TEM-1 and SHV-1 and problems with false susceptibility in disk diffusion tests. Antimicrob Agents Chemother 1988; 32: 1365-1369.

18. Seetulsingh PS, Hall LMC, Livermore DM. Activity of clavulanate combinations against TEM-1 $\beta$-lactamase producing Escherichia coli isolates obtained in 1982 and 1989. I Antimicrob Chemother 1991; 27: 749-759.

19. Wu PJ, Shannon K, Phillips I. $\beta$-Lactamases and susceptibility to $\beta$-lactam antibiotics in Escherichia coli. $J$ Antimicrob Chemother 1992; 30: 868-871.

20. Delaire M, Labia R, Samama J-P, Masson J-M. Site directed mutagenesis at the active site of Escherichia coli TEM-1 $\beta$ lactamase. Suicide inhibitor-resistant mutants reveal the role of arginine 244 and methionine 69 in catalysis. $J$ Biol Chem 1992; 267: 20600-20606.

21. Manavathu EK, Lerner SA, Fekete T, Perlin MH, Ziaja E, Price S. Characterization of mutant TEM $\beta$-lactamase that confers resistance to ampicillin (amp) plus clavulanic acid (CA). Abstracts of the 30th Interscience Congress on Antimicrobial Agents and Chemotherapy 1990; No. 281: 133. 